\title{
Clinical biochemistry of the neonatal period: immaturity, hypoxia, and metabolic disease
}

\author{
R A HARKNESS \\ From the Division of Inherited Metabolic Disease, Medical Research Centre, Harrow, Middlesex
}

SUMMARY This review attempts to provide practical information on common problems in the laboratory medicine of newborn infants and also considers unresolved problems in achieving neonatal diagnoses. A common cause of upset in the newborn-intrapartum asphyxia-can now be positively diagnosed. This leaves a small group whom it is necessary to investigate because they may have metabolic disease. The initial investigation of metabolic disease at the district general hospital should be limited to the commoner conditions.

This review aims to present everyday practice of clinical biochemistry in the neonatal period and to consider how cases which need more detailed consideration by a laboratory medicine team might be selected. The neonatal period is from birth to four weeks of age. Newborn infants require special care, generally for immaturity. For those few whose condition does not improve with age, a system of investigation can be devised. Fig 1 shows the basis for such an approach.

For a baby born after a 40 week gestation the most likely cause for upset is hypoxia during birth; the nonspecific but extremely variable clinical changes produced by hypoxia decrease with time after birth. On discharge from hospital at about 7-10 days no obvious ill effects may be detectable, but the infant is on total bed rest and constantly nursed. Later in life increased demands on the central nervous system made by reading and writing ${ }^{1}$ or the necessity of secreting more growth hormone ${ }^{2}$ may show up defects. Infections, like congenital malformations and metabolic disease, tend to get worse. The pattern of events over time is of major diagnostic importance. In a preterm infant time also allows the clusters of adaptive changes, described as maturation, to take place and in all infants permits the healing of birth trauma. The success of many of the supportive procedures like increased oxygen concentration and even ventilation in preterm infants depends on such maturation.

When the infant does not mature normally then a wide variety of conditions are caused. Anatomical defects can be detected clinically or by various imaging techniques, failing which, they may eventually be shown at necropsy. Congenital disease of the heart, gut, or renal tract is often clinically apparent. Such clinically obvious disease is generally detected using a systematic clinical approach. Serious defects which are not obvious require conscious search with a specific screening procedure. Congenital dislocation of the hip and phenylketonuria are examples which 8 are not fatal but later produce obvious and serious "disease".

Much has been written about the neonatal period. Books selected or written by local clinical staff are obviously the best guide to local clinical practice, but many of them are long. There are also a few extremely practical guides to clinical practice, but little help is available for those in laboratory medicine. The physiological principles entailed in the care of the newborn, especially preterm infants, have been reviewed ${ }^{3}$ in addition to the relevant clinical biochemistry procedures. ${ }^{4}$ Both these reviews focus on the principal workload of special care baby units that is generated by the problems of immaturity: "normal" values for conventional clinical biochemical results in newborn infants have been compiled. ${ }^{5}$

The available reference values in the fetus and the newborn need to be interpreted with caution as these are often generated at or after delivery when there might be undiagnosed asphyxia present. Asphyxia can raise fetal inorganic phosphate and sulphate concentrations, thus generating an apparent fetalmaternal gradient which may not have existed during intrauterine life. Such a gradient has already been noted for sulphate concentration at delivery. The inclusion of values from infants with undiagnosed intrapartum asphyxia may also be responsible for the high upper limits of reference ranges for newborn in- 


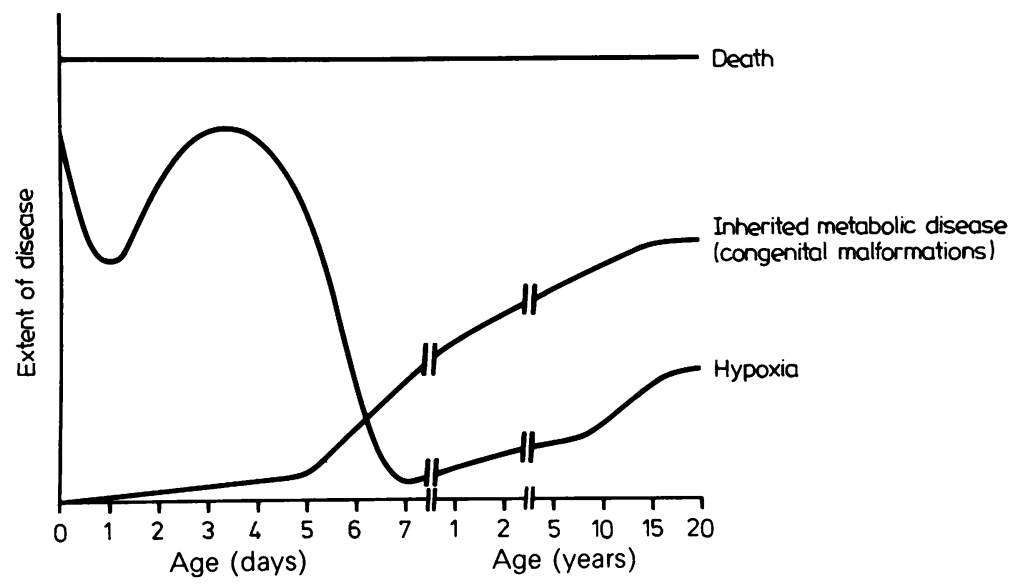

Fig 1 Changes seen in the patterns of disease intensity with age. Improvement with age occurs after trauma and in the common effects of immaturity and hypoxia.

Deterioration with age occurs in the effects of infection, congenital malformations, and inherited metabolic disease.

fants. The values used at Northwick Park Hospital, for example, are uric acid concentration 90-580 $\mu \mathrm{mol} / \mathrm{l}$, serum aspartate transferase activity $30-75$ IU/l, creatine kinase 40-500 IU/l and $\gamma$ glutamyl transferase activity $12-200 \mathrm{IU} / \mathrm{l}$; the urate is a byproduct of the increased purine output associated with adenosine triphosphate (ATP) depletion and the leakage of enzymes from cells depleted of ATP causes the high upper limits for the enzyme activities.

This paper aims to help those workers in laboratory medicine in hospitals which deliver between 1000 and 4000 babies each year. Some responsibilities for newborn infants will probably be a part of their routine work and a relatively large part of their emergency work. Units with smaller numbers of deliveries will probably refer their perinatal problems, preferably in utero, or failing that, in ambulances.

Attempts are made later in this review to integrate the every day care of the newborn with the problems of diagnosis of metabolic disease. The small range of diagnoses made in special care baby units contrasts with the long lists of possibilities and the success of some screening programmes. ${ }^{6}$ Antenatal diagnosis must also be mentioned as it is one factor that affects the incidence of open neural tube defects ${ }^{7}$ and chromosomal anomalies. ${ }^{8}$

\section{Routine laboratory care of the newborn}

\section{GENERAL CONSIDERATIONS}

Most newborn infants require no special care. About $10 \%$ are admitted to a special or intensive care unit from which many emergency requests can arise. New- born infants change rapidly, and specimens for analysis should be transported rapidly and biochemistry reports should be available twice daily to reduce the errors and interruptions inherent in telephone reports. There is also a place for coordinated ward laboratories used by medical and nursing staff to carry out simple tests that are urgently needed.

Local experience is used extensively as the basis of this review. Such personal practice, however, may not always be suitable for a different environment. Furthermore, accepted practice may not always have been adequately evaluated and may reflect the past rather than the present. Accepted practices like the extensive use of measurements of sodium and potassium concentrations are difficult to evaluate and it is even more difficult to change their use. If practice is not to become frozen into existing rituals it is advisable to evaluate the uses and limitations of all procedures, including those performed by nurses. Some laboratories have stopped measuring chloride without ill effects, and this indicates that large changes can be made safely. Safe reductions in emergency requests can also be achieved by medical laboratory staff. ${ }^{910}$

\section{ANTENATAL CARE}

Biochemical care of the newborn begins in the antenatal ward: routine clinical biochemistry is of little benefit. The obstetrician wants to know the fetal age, size, presentation, and fetal risk. Clinical biochemistry can be fittingly used to measure fetal risk.

\section{Pulmonary maturity}

In preterm infants pulmonary immaturity is a major problem. ${ }^{11}$ Treatment by prolonged ventilation and 
increased oxygen concentrations is expensive and not entirely safe. In a pregnancy of less than 36 weeks the assessment of pulmonary maturity by amniotic fluid phospholipid concentration-either by thin layer chromatography relative to the internal standard of endogenous sphingomyelin concentration or by more quantitative methods ${ }^{12}{ }^{13}$-provides information on the risk of respiratory distress. It is true that such investigations are not necessary if the baby must be delivered for obstetric reasons. Evaluation of obstetric risk, however, is usually imprecise, and delays in delivery are often justifiable because clinical experience shows that the stimulation of pulmonary development for 48 hours before delivery by glucocorticosteroids is effective.

\section{Rhesus isoimmunisation}

The extent of Rhesus isoimmunisation can be estimated by spectrophotometric estimations of bilirubin in filtered amniotic fluid. ${ }^{1213}$ These results offer a precise guide to treatment, including intrauterine transfusion.

\section{Oestrogen analyses and time intervals sampled by different procedures}

Measurements of fetal size by ultrasound scanning may detect fetal growth retardation over an interval of one or more weeks. The biochemical function of the growth retarded or at risk fetoplacental unit can be estimated from oestrogen excretion over 24 hours. If three or more results show a consistent fall to concentrations below normal the risk to the fetus is high. If oestrogen excretion is consistently $<20 \mu \mathrm{mol} / 24$ hours but with normal fetal growth, steroid sulphatase deficiency is probable ${ }^{14}$ and presents little or no risk except at birth. ${ }^{15}$ Measurement of blood oestrogen concentrations can be informative over a shorter time interval of about three hours; monitoring of fetal heart rate gives an instant record. The usefulness of oestrogen analyses in diagnosing specific defects of the fetal hypothalamo-pituitaryadrenocortical-placental system and the low usefulness of these results in indicating general metabolic failure has been discussed, as have the differences between blood and urinary oestrogens. ${ }^{16}$

To avoid spurious conflicts a coordinated approach is required for the allocation of resources between methods which provide different information or study different time intervals. The routine application of any of the above monitoring methods to an unselected population can provide little or no benefit. A combined systematic approach using a preliminary screening method is difficult to evaluate as developments, especially in ultrasound scanning techniques, are changing this area. It is often difficult to control the quality of ultrasound observations and the interpretation of fetal heart rate patterns in routine clinical work.

\section{Rationalisation}

Requests for analyses of amniotic fluid for $\overrightarrow{\overrightarrow{\vec{s}}}$ phospholipids and bilirubin, as well as urinary $\frac{?}{0}$ oestrogen excretion, are decreasing to a point where $\frac{C}{0}$ it is difficult for any district hospital laboratory to $\frac{\bar{\sigma}}{\overline{0}}$ produce reliable results. As these analyses can be use- $\vec{\nabla}$ ful, regional centres for these measurements should now be agreed.

CLINICAL BIOCHEMISTRY IN SPECIAL AND

INTENSIVE CARE NEONATAL UNITS

Much of this can be done in the ward by clinical and nursing staff using side room equipment. ${ }^{17} 18$

Small volumes of blood are all that can be spared in infants weighing about $1 \mathrm{~kg}$. For the central laboratory the provision of a service using very small quantities of blood is difficult. "Top up" transfusions are to be avoided because of their attendant risks of viral infection, especially hepatitis. Junior medical staff are probably the most practical and skilled source of blood samples, using indwelling catheters, peripheral veins, or capillaries. In this way disturbance can be minimised and the volume taken can be easily monitored. It is necessary for laboratory staff to spend considerable time and effort in using as much as posê sible of the samples. It is surprisingly simple to scale down a modern routine method so that only micros litre samples will be needed. Small specimen tubes sampled carefully using thin pipette tips and more staff time are all that may be needed to provide an improved "micro" service.

Anoxia The first need of a newborn infant is for oxygen. The monitoring of ventilatory efficiency in preterm infants with pulmonary immaturity or in infants with asphyxial lung damage is efficiently and continuously performed by transcutaneous $\mathrm{pO}_{2}$ monitoring with periodic checks of blood acid base and gas variables $-\mathrm{pH}, \mathrm{pO}_{2}, \mathrm{pCO}_{2}$, base excess, and standard bicarbonate.

Salt and water balance and renal function The second major need is for water and minerals, although some regimens for the treatment of intrapartum hypoxic damage restrict fluid intake "to reduce cerebral oedema". In addition to measuring urine volume, nurses use refractometers and dipstick methods to measure the specific gravity of urine. The dipstick methods can also detect renal damage manifest as proteinuria and haematuria. Accepted clinical practice is to use serum urea concentration as an index of renal failure but experience in paediatric nephrology suggests that measurement of serum creatinine is better. Renal failure in the first two days of life is a feature of the damage caused by intrapartum asphyxia 
and is seen as oliguria or anuria.

When oral feeding is difficult or impossible, or in cases with excessive gut or even renal losses, monitoring serum sodium and potassium concentrations is useful especially if combined with measurements of serum creatinine. Renal immaturity in preterm infants can also result in excessive loss of renal sodium which can be treated with supplements. Diagnostically confusing amounts of lactose and galactose as well as amino acids are also found in urine from preterm infants.

Hypoglycaemia The third major need is for an energy source. Hypoglycaemia can occur in the newborn, particularly in preterm infants who have inadequate glycogen stores and an inability to perform gluconeogenesis, and in the infants of diabetic mothers. Hypoglycaemic infants may have used their glycogen stores during intrapartum asphyxia. Regular ward monitoring of blood glucose with dipsticks or tapes is standard practice. The role of the laboratory is to confirm the dipstick results for which a fluoride blood sample is advisable. ${ }^{19}$

Hypocalcaemia Another example of physiological immaturity is hypocalcaemia. This can also follow intrapartum hypoxia, possible due to defective renal hydroxylation of 25-hydroxycholecalciferol. Experienced clinicians will recognise slight "jitteriness" as a good guide to this condition. Measurement of serum or plasma calcium is therefore often requested and the results of treatment are good. ${ }^{20}$ Only if there is no response to a calcium supplement for about three days is it justifiable to measure serum magnesium. Hypomagnesaemia complicating hypocalcaemia has been reported and both respond well to supplementary magnesium. Hypomagnesaemia alone is virtually unknown: emergency magnesium estimations cannot therefore be justified. It is rare for any infants to require further investigation for any of the diseases associated with incorrect calcium metabolism despite clear and even recurrent evidence of neonatal hypocalcaemia. Such investigations are only practicable in a metabolically stable and mature infant.

Jaundice The immaturity of detoxication systems is seen in the "physiological" jaundice of the newborn, in which rapid breakdown of fetal haemoglobin and its further metabolism can not be adequately performed by the liver. Unconjugated bilirubin concentration rises to a peak at 3-5 days of age, and this may be measured by various side room bilirubinometers that simply measure the yellow colour of plasma or serum, or even skin. These are adequate at bilirubin concentrations of less than $200 \mu \mathrm{mol} / 1$ and can monitor the effects of phototherapy as well as hepatic maturation, thus saving the laboratory a large load of emergency and routine bilirubin estimations. These instruments are less reliable, however, at high concentrations, and laboratory methods are needed for clinical decisions such as exchange transfusion. ${ }^{17}$ Jaundice is the clearest example of a condition which is, initially, nearly always "physiological immaturity." If it persists and especially if a pronounced rise in conjugated bilirubin occurs investigation is required.

The "problem oriented" case record has been used in the systematic investigation of neonatal jaundice by Mathew and Wharton. ${ }^{21}$ Their chart showing serial plots of plasma bilirubin against age in days, with an action limit for phototherapy at about 250 $\mu \mathrm{mol} / \mathrm{l}$ and that for exchange transfusion at about $350 \mu \mathrm{mol} / 1$, is similar to charts used in many units. Their careful documentation of experience with infants born in $1976(n=1988)$ suggested that their action limits may need changing and that the selection of tests which are going to yield useful diagnoses for their population should be changed. Possible ABO incompatibility was common (34 cases) but unsuspected infection was rare (four cases), and transient and questionable hypothyroidism occurred in four preterm infants. Congenital hyperbilirubinaemia was found in three cases with probable neonatal "hepatitis". There were two infants with chronic illness, one with a "pulmonary syndrome", and another had propionic acidaemia that was unresponsive to biotin. Neither glucose-6-phosphate dehydrogenase deficiency nor galactosaemia were detected in any infant. A systematic review of the investigation of jaundice will produce an effective local protocol.

Breast milk jaundice The incidence of breast milk jaundice is between 1 and $2 \% .{ }^{22}$ As the milk of a species is adapted to the nutrition of that species ${ }^{23}$ breast feeding is encouraged. Breast feeding has again become more popular in some areas of the United Kingdom. ${ }^{24}$ Detailed consideration of breast milk jaundice is thus justified. The mean rise in bilirubin concentration in breast fed infants may be no larger than in formula fed term but not preterm infants. ${ }^{25}$ In $1-2 \%$ of mother and infant pairs, however, there is an icterogenic effect of human but not cow's milk.

The often cited association between $5 \beta$-pregnane-3 $\alpha, 20 \beta$-diol in human milk and jaundice came from New York. It has been confirmed that $5 \beta$-pregnane- $3 \alpha, 20 \beta$-diol was present in lactating mothers with jaundiced infants ${ }^{26}$ but disappeared after the end of lactation. These mothers probably had some abnormality of the steroid metabolism of the lactating mammary gland. The predominantly $5 \alpha$ structure for steroids in milk and studies of mammary gland metabolism in vitro suggest that the breast changes the pattern of steroids in milk from that in plasma. ${ }^{2728}$ Large doses of steroids can raise unconjugated bilirubin concentrations in plasma in the new- 


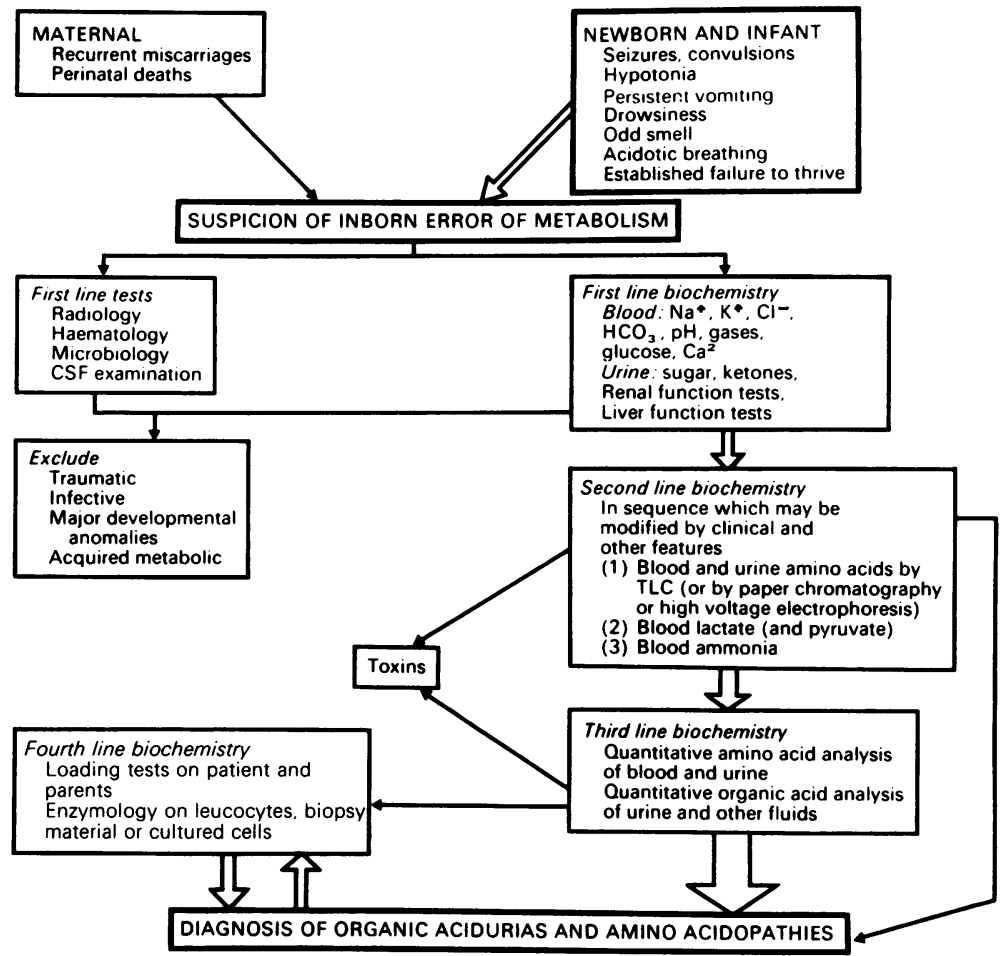

Fig 2 Scheme for the diagnosis of organic acidurias and amino acidopathies in sick children. ${ }^{90}$

born, ${ }^{29}$ and milk causing jaundice was inhibitory in vitro to glucuronyl transferase activity. Such inhibition, however, was not explained by the effects of $5 \beta$-pregnane- $3 \alpha, 20 \beta$-diol. ${ }^{30}$

General consideration of bilirubin metabolism suggested that a wide variety of medium molecular weight compounds could be responsible for breast milk jaundice. ${ }^{31}$ Many steroids inhibit steroid glucuronyltransferase activity with similar micromolar inhibition constants ${ }^{32}$ and might therefore inhibit bilirubin detoxication by these enzymes. A survey method, suitable for the identification of peaks using gas chromatography-mass spectrometry (GC-MS), was applied to milk. ${ }^{33-36}$ The method showed a low concentration of pregnanediones from pregnanediols and pregnanolones in human milk (table 1), with no increases found in milk causing breast milk jaundice. Another sensitive GC-MS method did not detect pregnanediols in human milk. ${ }^{37}$

Many studies on the transmission of steroid analogues, ${ }^{3839}$ other drugs, ${ }^{40}$ and insecticides ${ }^{41}$ in milk have shown low concentrations. Any such compound found in milk has been of a low and usually biologically unimportant dose; the exceptions have been listed in advice to prescribers. ${ }^{42}$
Table 1 Steroids in human milk from mothers with jaundiced $(n=9)$ and normal $(n=6)$ infants

\begin{tabular}{|c|c|c|c|}
\hline $\begin{array}{l}\text { Normal } \\
\text { infants* }\end{array}$ & $\begin{array}{l}\text { Age } \\
\text { (days) }\end{array}$ & $\begin{array}{l}\text { Steroid detected in GC } \\
\text { survey }\end{array}$ & $\begin{array}{l}\text { Quantity in } \\
\text { final fraction } \\
(\mu \mathrm{g} / 100 \mathrm{ml} \text { milk })+\end{array}$ \\
\hline $\begin{array}{l}1 \\
2 \\
3\end{array}$ & 4 & $\begin{array}{l}5 \alpha \text { androstane- } 3,17 \text {-dione } \\
5 \beta \text { pregnane- } 3,20 \text {-dione } \\
5 \alpha \text { and } 5 \beta \\
\quad \text { androstane- } 3,17 \text {-dione } \\
5 \alpha \text { pregnane-3,20-dione } \\
5 \alpha \text { androstane-3,17-dione }\end{array}$ & $\begin{array}{l}0.57 \\
0.08 \\
0.12 \text { and } 0.12 \\
0.12 \\
0.29\end{array}$ \\
\hline \multicolumn{4}{|c|}{ Jaundiced infants* } \\
\hline $\begin{array}{l}1 \\
2 \\
3\end{array}$ & $\begin{array}{r}5 \\
14 \\
15 \\
17\end{array}$ & $\begin{array}{l}5 \alpha \text { androstane-3,17-dione } \\
5 \beta \text { androstane- } 3,17 \text {-dione } \\
5 \alpha \text { androstane-3,17-dione }\end{array}$ & $\begin{array}{l}0.46 \\
0.07 \\
0.15 \\
0.16\end{array}$ \\
\hline 4 & $\begin{array}{l}18 \\
23\end{array}$ & $5 \alpha$ androstane-3,17-dione & $\begin{array}{l}0.17 \\
0.21\end{array}$ \\
\hline 5 & $\begin{array}{l}28 \\
42 \\
63\end{array}$ & $5 \alpha$ androstane-3,17-dione & $\begin{array}{l}0.06 \\
0.27 \\
0.21\end{array}$ \\
\hline 6 & $\begin{array}{l}84 \\
21\end{array}$ & $\begin{array}{l}5 \beta \text { androstane-3,17-dione } \\
5 \beta \text { pregnane- } 3,20 \text {-dione }\end{array}$ & $\begin{array}{l}0.06 \\
0.29\end{array}$ \\
\hline
\end{tabular}

*Milk from three mothers with jaundiced infants and from two mothers with normal infants contained no detectable steroids. t0.50 $\mu \mathrm{g} / 100 \mathrm{ml}=14 \mathrm{nmol} / \mathrm{l}$.

Data from JAB Darling, the Department of Paediatric

Biochemistry, Royal Hospital for Sick Children, Edinburgh. 
It was clear from gas chromatography (figs 1 and $2)^{67}$ and from thin layer chromatography evidence that human milk contained more lipid soluble medium molecular weight compounds than cows's milk. There was, however, no component on thin layer chromatography or gas chromatography that was associated with jaundice in the infants receiving the milk (Darling and Harkness, unpublished observations, 1975). There were, therefore, more potential inhibitors in human milk ${ }^{30}$ but no one compound and certainly no pregnanediol could account for the jaundice. The evidence suggests that some breast milk jaundice is due to cumulative inhibitory effects from small amounts of many compounds on bilirubin detoxication and excretion. Many different compounds are detoxicated by the same mechanisms as bilirubin; specifically, the glucuronyl transferases are "receptors" of wide specificity. ${ }^{32}$

Care should be exercised in checking the specificity of analytical methods used on milk: it has not proved possible to confirm reports of high vitamin D sulphate concentrations in milk based on a colourimetric method. ${ }^{43}$

The large numbers of compounds in human milk may arise from a highly varied diet compared with that of dairy cattle. Specifically, it seems pointless to analyse milk for pregnanediols.

\section{MAINTENANCE OF WARD AND SIDE ROOM METHODS}

Mention has been made of the techniques whereby ward blood glucose monitoring can be checked and its quality maintained. The laboratory can also usefully train medical and nursing staff and check their performance. ${ }^{17-19} \mathrm{~A}$ simple technique to reduce anomalous results is for the performance of the actual bottle of sticks used to be checked. A poor batch may result from changes that have occurred during storage, or from operator errors. Quality control for the bilirubinometer can in practice depend on comparison of results from ward and laboratory from the same patient at about the same time. ${ }^{17}$ The increasing use of dry stick methods is clinically desirable and will increase.

A simple and robust instrument like a refractometer used for measurements of urine specific gravity or a bilirubinometer in a side room may only need to be cleaned after use. A stock of commonly needed spares must also be kept. These requirements can be efficiently handled at ward level.

Complex machinery like existing blood gas assemblies requires regular quality control and service checks by laboratory staff. The machine must therefore be in continuous use to compensate for the work needed to maintain it in good order, otherwise, it should be placed in the general laboratory medicine area.

A careful and agreed definition of responsibilities in the area of ward and side room methods, with a continuing communication network among designated staff can avoid unnecessary conflicts. In the NHS this is difficult except at consultant level. The recommended guidelines on the performance of chemical pathology assays outside the laboratory ${ }^{18}$ provides a useful guide to harmonious working practices.

NEWER DEVELOPMENTS: DRUG MONITORING Expensive developments in laboratory methods are an ongoing problem for those assigning resources. After enthusiasts show that their procedure can be useful there is a need for critical assessment of cost and of benefit and a clear description of where and how such methods can solve or prevent clinical problems.

Drug monitoring is potentially one of the most expensive areas of laboratory medicine and may be of particular importance in the newborn period because the neonate lacks the necessary detoxication systems. The vulnerability of developing systems is also high: examples are the sensitivity of multiplying mitochondria to chloramphenicol ${ }^{44}$ and of myelin to hexachlorophene. ${ }^{45}$

The prescription of antibiotics on suspicion or risk of infection is common in special care baby units, although less than $40 \%$ of neonates have any definite evidence of infection. Gentamicin is often used which requires regular monitoring to avoid toxicity. Another widely used drug, which is regularly monitored in the newborn, is theophylline, a stimulant to the respiratory centre used in preterm infants who have periodic apnoea. Apnoea is usually well tolerated and occurs about five to seven days after delivery when the baby has excreted the caffeine derived from its mother. Methylated xanthines have very much longer half lives in newborn infants than in adults. Although good cost benefit assessments are not available, the use of theophylline in the newborn has been reviewed. ${ }^{46}$

The use of drugs only on specific indications is advisable but this is difficult in practice. The intensive efforts made to save newborn infants, especially preterm infants, require the administration of many potent drugs. To avoid unnecessary side effects the safest course would be to improve the standards of diagnosis, an area in which laboratory medicine has a major role.

\section{THE CHRONIC CARE OF PRETERM INFANTS}

Once the problems of pulmonary immaturity are over, the care of preterm infants focuses on nutrition, which makes great demands on mothers and nurses. 


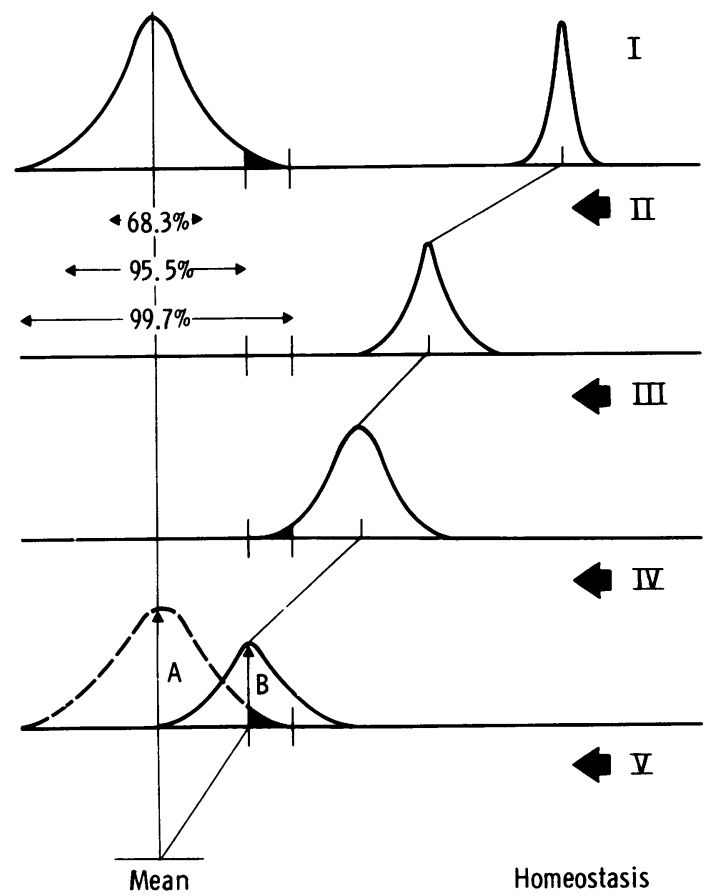

Fig 3 Convergence of processes to produce any final product allows homeostasis to mask a defect five stages away from its initial cause (line 1). Unless variables at or near the primary defect are measured, overlapping values will be found (lines 3 and 4). Lines 1-5 represent values of different variables in a chain of causal events. The values of the different variables are plotted as standard deviations of the normal population from the mean. The relative amounts of the normal "population" encompassed by 1, 2, and 3 standard deviations, 68.3, 95.5 , and $99.7 \%$ respectively, are indicated below the normal distribution.

The excess loss of sodium caused by the failure of the kidney to respond to aldosterone can be detected by regular estimations of serum sodium and potassium. Calcium deficiency can also occur and cause rickets; radiological diagnosis is unequivocal but not soon enough. Gross increases of alkaline phosphatase activity in plasma can be shown but the wide variation in normal values still renders interpretation of early changes difficult.

\section{Diagnosis in the newborn}

The need for transient "homeostatic" care conceals many diagnostic problems. A widely adopted solution is to conduct diagnostic investigations only if the state of the baby does not improve with time (fig 1). Many major and eventually fatal anomalies compatible with live birth also allow four to five days of extrauterine life. In the first two to three days of life the assumption that the major problems are transient products of immaturity and do not require a diagnosis is probably justifiable, but severe infections and intrapartum hypoxia must be diagnosed. At present both infections and intrapartum hypoxia are diagnosed on non-specific signs similar to those listed in table 2 and fig 2, indicating metabolic disease.

\section{DIAGNOSIS AND MEASUREMENT OF HYPOXIC}

DA MAGE

Intrapartum asphyxia is common, being severe enough to cause clinical problems in $1 \%$ of all births. ${ }^{47}$ Infection can usually be successfully treated by antibiotics. Anatomical abnormalities are detectable by detailed clinical examination and imaging techniques. The positive laboratory diagnosis of intrapartum hypoxia would help obstetricians and allow a small group of children to be selected who show signs attributable to hypoxia, but in whom inherited or congenital metabolic disease are considered more likely because they show no specific evidence of hypoxic damage. It is probable that in this group are found many of the permanent neurological defects previously ascribed to asphyxia. A variety of evidence 
suggests that we may be overdiagnosing asphyxia as a cause of long term handicap.

The diagnostic use of non-specific variables and the related overlapping distribution of variables Why are we continually trying to measure risk and even achieve diagnoses using overlapping distributions of variables? Because we use commonly disturbed variables which are the end products of many rarer, initial defects. Many different initial defects converge to produce a final effect like growth failure. Fig 3 gives an explanation of the overlapping distribution of variables, which represents values of several associated variables.

Most variables used in monitoring show poor discrimination between normal and abnormal (fig 3). This arises because the initial defects causing the disturbances are several stages removed, and the different linking stages are all subject to homeostatic mechanisms that tend to restore values to normal. In other words, the further away a measurement is made from the site of a primary defect, the greater the overlap produced by homeostasis between normal and abnormal distributions of values. Good discrimination is probably the reason for the consistent progress that is being made in the diagnosis and treatment of rare conditions. This progress contrasts with the negative or equivocal results of trials of methods detecting final common products, like intrauterine growth failure.

\section{Table 2 Features suggesting metabolic disease}

1 Clinical features and findings of routine investigations:

Persistent vomiting

Poor feeding, failure to thrive

Neurological abnormalities depressed consciousness from somnolence and lethargy to coma, convulsions, hypoventilation and hyperventilation, absence or loss of functions expected in the newborn, such as ability to suck and swallow

Liver abnormalities

Acute liver failure, jaundice, bleeding, depressed conscious state, large or small liver depending on stage of disease

Pronounced or prolonged jaundice

Hepatomegaly with or without splenomegaly

Metabolic acidosis

Abnormal smel

Unexplained hypoglycaemia

Neutropenia, thrombocytopenia, particularly with metabolic acidosis

Hyponatraemia/hyperkalaemia with or without ambiguous genitalia

Miscellaneous, and less commonly, diarrhoea, hypothermia, abnormal hair, cardiomegaly and heart failure, cataract

2 Important supporting factors:

Family history of similar incidents or unexplained death

Familial consanguinity

Onset of illness corresponds to a change of feeding practice, or the timing of symptoms related to feeds

Symptoms improve on glucose/saline fluids

Onset of illness associated with infection, fasting, or surgery.

Data modified from Holton JB. Ann Clin Biochem 1982;19:389-95.

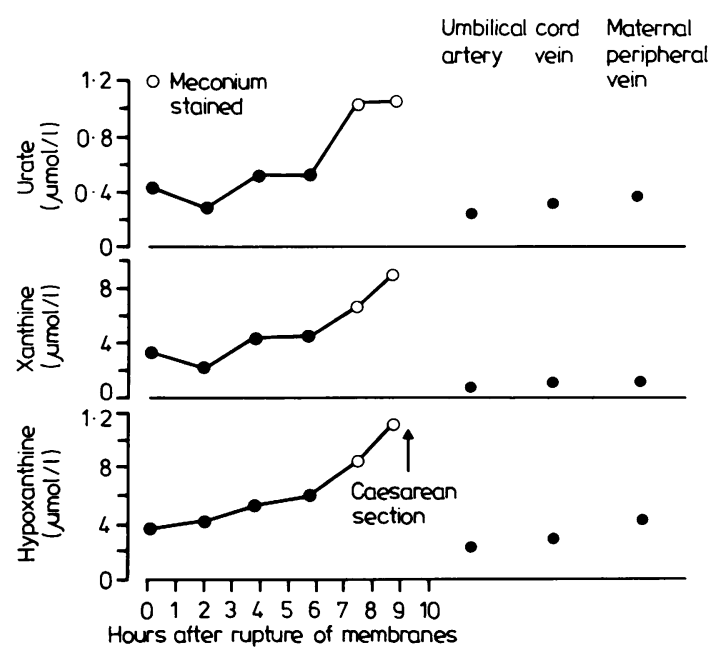

Fig 4 Amniotic fluid and cord blood plasma concentrations of hypoxanthine, xanthine, and urate from mother and child monitored during labour, showing criteria of fetal distress, fetal heart rate abnormalities, and meconium stained amniotic fluid.

Because several initial or primary defects converge to produce changes in growth, for example, growth failure is more common than any one individual primary or initial defect and is therefore a tempting target. Clinically, it is rarely practicable to measure each different primary or initial defect, but the routine detection of intrauterine growth failure by ultrasound examination is only useful in a high risk group because of the overlapping distributions of values.

Clinical assessment Clinical diagnosis and assessment of damage due to intrapartum hypoxia depend on non-specific signs, ${ }^{4849}$ many of which are ranked to produce a cumulative Apgar score. ${ }^{50}$ The Apgar score, however, is too insensitive to measure the efficacy of obstetric procedures which are now beginning to lower the stillbirth rate. If obstetric intervention is successful infants are born with high Apgar scores after showing signs of intrauterine hypoxia, such as slowing of the fetal heart following uterine contractions and meconium staining of amniotic fluid.

pH and blood gas variables The use of $\mathrm{pH}$ and blood gas variables in cord blood and even from fetal scalp to assess hypoxia are limited in their application. The period of time sampled is limited to about 30 minutes or less. ${ }^{51}$ The widespread evidence of a lack of correlation of cord blood pH or hypoxanthine ${ }^{5253}$ (fig 4) or newborn $\mathrm{pH}$ after resuscitation ${ }^{54}$ with fetal damage is largely due to the rapid changes of $\mathrm{pH}$ and other variables in blood. As labour generally lasts more than four hours a more "cumulative" record of hypoxic damage is needed. Moreover, most changes 
Hypoxanthine

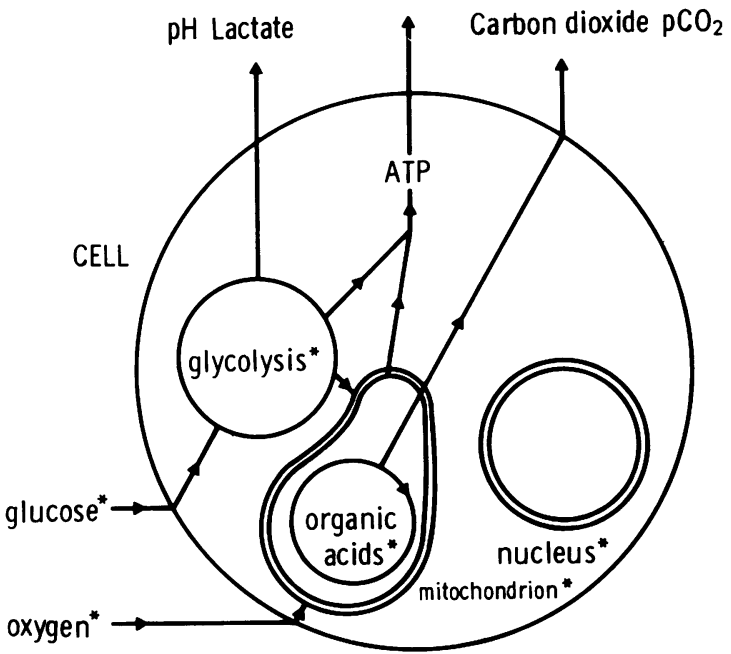

Fig 5 Energy generation in the cell by the mitochondria and cytosol using oxygen and glucose to produce the energy currency of the cell ATP. During depletion ATP is broken down to hypoxanthine. Glycolysis is reflected by lactate concentrations which can affect blood pH. The sites of defects in ATP generation are indicated by asterisks and include hypoxia, hypoglycaemia, and ischaemia, as well as intracellular defects in glycolysis, organic acid metabolism, other mitochondrial functions and a variety of genetic defects in nuclear DNA.

in $\mathrm{pH}$ are due to metabolic acidosis and reflect lactate concentrations which are produced by anaerobic glycolysis. Anaerobic glycolysis can maintain ATP concentrations in many tissues, especially in the fetus. Measurement of $\mathrm{pH}$ does not reflect a fall in ATP concentrations, which is the critical initial event in metabolic damage caused by hypoxia.

\section{ATP METABOLISM IN HYPOXIA}

New methods of assessment

It is possible to define asphyxia at the molecular level as a failure of energy supply sufficient to cause cellular damage. As the energy currency of cells is the purine nucleotide ATP the definition is, "ATP depletion sufficient to cause irreversible or partially reversible cellular damage," (which also covers damage by hypoglycaemia). ATP is confined to living cells but ATP depletion can be measured in extracellular fluids because such depletion increases output of hypoxanthine, the central intermediate product in purine metabolism, from tissues into blood, urine, amniotic fluid and cerebrospinal fluid. The mechanisms and quantitative associations between concentrations of hypoxanthine and tissue energy supply have been established. ${ }^{55-60}$ Fig 5 represents the information pro- vided by lactate on the rate of glycolysis and by hypoxanthine on the extent of ATP depletion.

The relation between ATP depletion and subsequent tissue damage is more difficult to establish. ${ }^{6162}$ Unexpectedly, there is a close positive correlation between neurological damage, assessed clinically, and persistently excessive hypoxanthine excretion occurring 24 hours after ATP depletion and lasting for several days. ${ }^{5463}$

Anatomical origin of the changes in ATP metabolites and methods of sampling for clinical analysis

Evidence from studies of progesterone and human
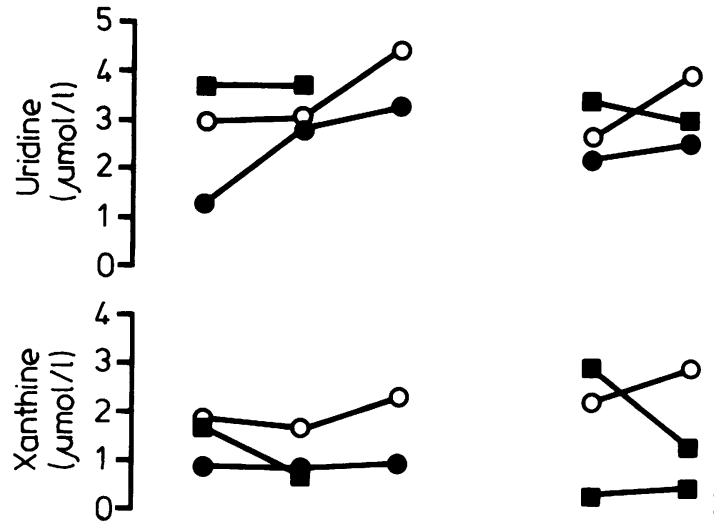

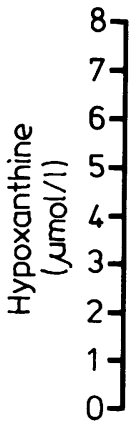
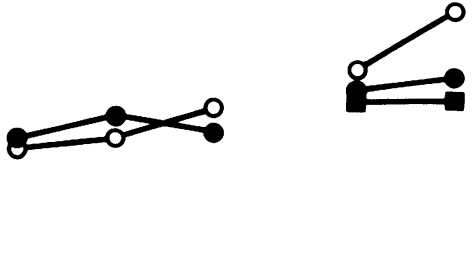

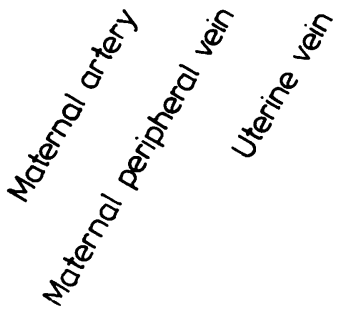

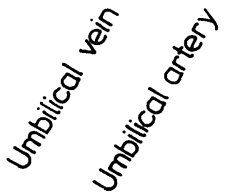

Fig 6 Plasma concentrations at elective operative deliveries of hypoxanthine, xanthine, and uridine in samples from maternal artery, peripheral vein, and uterine vein, as well as fetal umbilical vein and artery. Individual patients and their infants are shown by the symbols $\bigcirc, \bigcirc$, and $\square$. 
placental lactogen production shows that the fetus, and especially its brain, is more easily damaged than the placenta. Systematic studies on this area have been made in sheep. ${ }^{64}$ In man the vulnerability of the fetus was shown from studies of concentrations of ATP metabolites and the related pyrimidine nucleoside uridine present in maternal artery, peripheral and uterine veins, and fetal umbilical vein and artery samples at operative delivery. Fig 6 shows the results from
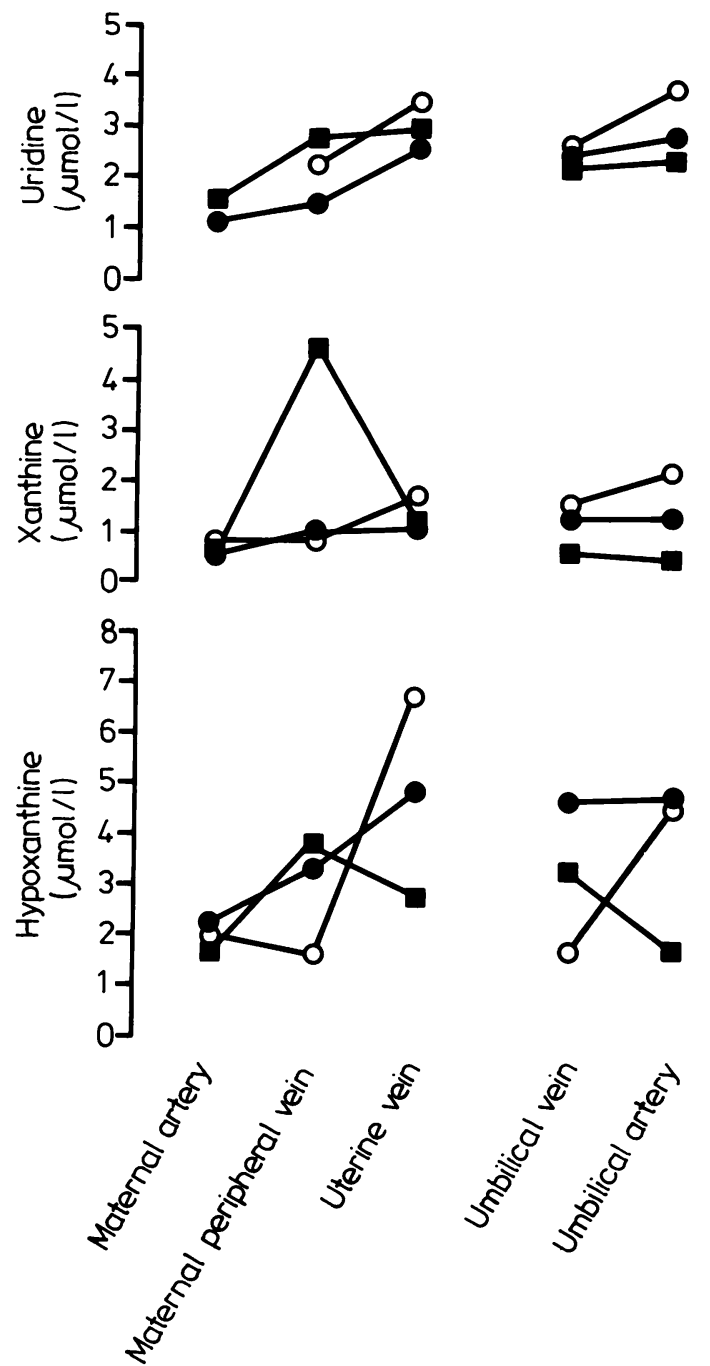

Fig 7 Plasma concentrations of hypoxanthine, xanthine, and uridine samples at emergency operative deliveries from maternal artery, peripheral vein, and uterine vein, as well as from fetal umbilical vein and artery. These patients and their infants had only one criterion of fetal distress and are shown by the symbols $\bigcirc, 0$, and $\square$. elective operative deliveries. There is no steep gradient, suggesting that there is no excess ATP breakdown in the normal fetus. In contrast, emergency operative deliveries without evidence of fetal distress show a trend for higher hypoxanthine concentrations in the uterine vein (fig 7), consistent with the active myometrium consuming ATP and releasing hypoxanthine. In cases with two or more clinical criteria of fetal distress, however, the increases in metabolites in uterine vein and umbilical artery compared with umbilical vein (fig 8) are consistent with a sharp increase in hypoxanthine output due to ATP breakdown by the fetus but not the placenta during fetal distress. The increases in uridine concentrations show a somewhat more consistent pattern and are compatible with the hypoxanthine concentrations (figs 6-8).

The slower breakdown of ATP in the placenta compared with that of the fetus has been confirmed in the rat and guinea pig. Their tissue concentrations of hypoxanthine, xanthine, and uridine are also significantly negatively correlated with the relative ATP concentrations expressed as energy charges. ${ }^{65}$ Similar correlations also exist in human placenta. ${ }^{66}$

The changes occurring in amniotic fluid over a considerable time period, possibly of about 12 to 24 hours, however (fig 4), ${ }^{6768}$ and later in neonatal urine give more diagnostic information than the rapid changes in blood and tissues. Fig 4 shows an abnormally high concentration of hypoxanthine in amniotic fluid in association with meconium staining, and fetal heart rate patterns justifying emergency caesarean section. The umbilical artery and vein concentrations and those in maternal peripheral vein returned to normal. The study in fig 4 thus illustrates the weak correlation of the rapidly responsive cord blood variables with antecedent state. It is also clear that obstetric intervention removes evidence of asphyxia. Amniotic fluid concentrations of hypoxanthine may thus become a means of validating and measuring the common obstetric diagnosis of fetal distress. ${ }^{6768}$

Although the placenta can be a source of tissue for enzymological confirmation of a diagnosis, ${ }^{69}$ there is no good biochemical evidence that placental insufficiency exists apart from arylsulphatase $\mathrm{C}$ or steroid sulphatase deficiency. ${ }^{14}$ Many routine procedures which assess the placenta are therefore of dubious value. In the more vulnerable fetus cerebrospinal fluid can be analysed to obtain a neurological prognosis from the hypoxanthine concentration. 55565960 Hypoxanthine output in urine and amniotic fluid are a record of hypoxia over about the previous 24-48 hours. ${ }^{5758}$ Analyses of these fluids in varying combinations may therefore help diagnose and assess the effects of intrapartum asphyxia ${ }^{6768}$ and cardiac and ventilatory arrest. 
Tissue damage after ATP depletion

A wealth of clinical and experimental evidence from drowning ${ }^{70}$ shows that it is the duration of anoxia relative to the irreducible energy requirements associated with an organ's temperature which determine the reversibility of the changes. After 10 minutes of extrauterine anoxia the prognosis is poor. In perfused rat hearts the duration of low ATP concentrations seems

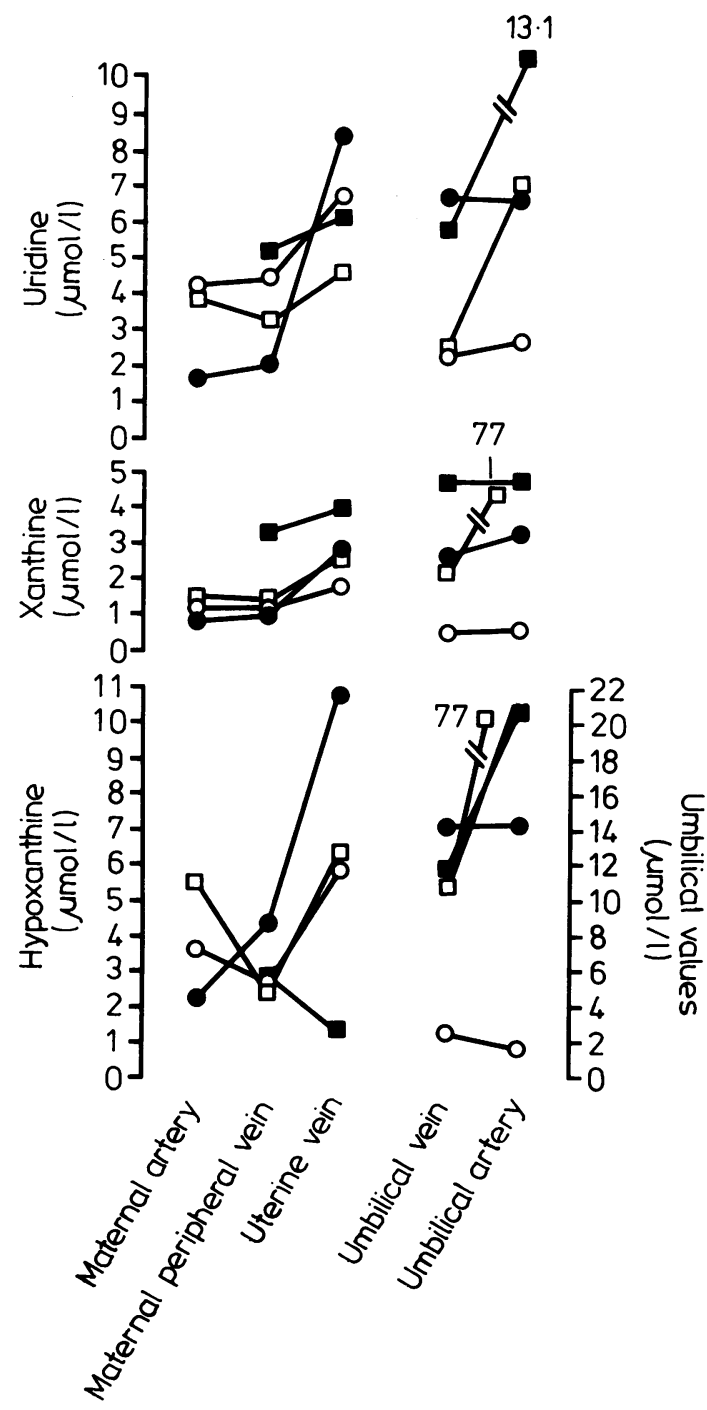

Fig 8 Plasma concentrations at emergency operative deliveries of hypoxanthine, xanthine, and uridine in samples from maternal artery, peripheral vein, and uterine vein, as well as fetal umbilical vein and artery. The infants showed two or more criteria of fetal distress and are shown by the symbols $\bigcirc, \bigcirc, \square$ and $\square$. to be related to the ability of the tissue to recover. ${ }^{71}$ If $\frac{}{5}$ glycolysis succeeds in maintaining ATP concen- $\stackrel{0}{\rightleftharpoons}$ trations then no damage will occur; a case of intra- 으 partum hypoxia has been reported with a pH of $6.6 \ddot{\Rightarrow}$ and a bicarbonate concentration of $12.9 \mathrm{mmol} / \mathrm{l}$ at $\stackrel{0}{\rightarrow}$ one hour with good recovery. ${ }^{72}$

Evidence from exercise and muscle physiology sug- 흠 gests that there are coordinated muscle and neural $\frac{\infty}{\vec{D}}$ mechanisms of fatigue that normally limit the energy $\stackrel{\mathbb{Q}}{\unrhd}$ drain and fall in ATP concentrations, so that they are easily reversible. ${ }^{73}$ Forcing the heart to work during $\vec{\circ}$ anoxia increases the amount of damage. It could be that the adverse effect of pronounced hyperglycaemia $\overrightarrow{\vec{\omega}}$ on anoxic brain damage ${ }^{74}$ is caused by the increased $\stackrel{\odot}{\circ}$ effort required to metabolise high glucose concen- $\frac{8}{8}$ trations.

Clinically, diabetes mellitus predisposes to intrapartum asphyxia. High fructose concentrations deplete liver adenosine phosphates, ${ }^{75}$ which reconciles $\vec{N}$ the experimental observations of Myers $e t a l^{74}$ with a variety of well established clinical observations. A normal glucose concentration seems to preserve brain $\vec{D}$ function in the fetus, and in extrauterine life hypo- $\mathbb{D}$ glycaemia damages the brain. Glycogen stores are $\underset{\mathbb{D}}{\mathbb{D}}$ rapidly used by tissues to maintain ATP concen- 3 trations and their absence in the fetus leads to dam- $\stackrel{\mathbb{D}}{-}$ age. ${ }^{64}$

\section{Recovery from damage}

Vogt and Farber ${ }^{76}$ showed that the reversibility change was a reliable prognostic index in the rat kidney. This also seems to be true for the rat heart. ${ }^{71}$ It is the degree of function in EEG records that can be maintained after the episode which relates to progno- $\mathbb{Q}$ sis. $^{70} 77$

\section{Diagnosis of metabolic disease at the district general hospital}

Two approaches have been used in the diagnosis of inherited metabolic diseases-stepwise analysis and population screening. Both have limitations and neither is of value in conditions which are rapidly fatal.

\section{CONVENTIONAL CLINICAL INVESTIGATION}

The classic stepwise approach of clinical medicine, $\frac{T}{O}$ which progressively limits the possibilities, can be highly effective. In addition to the infant's history, a $N$ family history may suggest an inherited disease. Re- N peated obstetric problems suggest a maternal cause, $\mathbb{N}$ which is often ill defined. Diagnostic success for the $\omega$ stepwise approach involving several groups and reference laboratories probably depends on a severe $\stackrel{\varrho}{\subset}$ progressive illness in which an infant stays alive only for months or years.

Cystic fibrosis can be diagnosed in this way. It is the 
Table 3 Approximate incidence of some metabolic diseases in populations of western European origin

\begin{tabular}{ll}
\hline Disorder & $\begin{array}{l}\text { Approximate No of } \\
\text { diagnoses per 100 000 births }\end{array}$ \\
\hline Cystic fibrosis & 50 \\
Neonatal hypothyroidism* & 25 \\
Other endocrine disorders $\dagger$ & 30 \\
Phenylketonuria & $5-25$ \\
(Histidinemia) & 6 \\
Homocystinuria & 1 \\
Maple syrup urine disease* & 1 \\
Urea cycle defects* & 4 \\
Cystinuria & 8 \\
Non-ketotic hyperglycinaemia* & 1 \\
Organic acidoses* & 3 \\
Galactosaemia & 2 \\
Other carbohydrate disorders* & 9 \\
Mucopolysaccharidoses & 8 \\
Other storage disorders & 19 \\
\hline
\end{tabular}

* Can cause acute disorder in the perinatal period.

† Mainly steroid 21-hydroxylase defects and arylsulphatase $\mathrm{C}$ or steroid sulphatase defects.

Data modified from Association of Clinical Biochemists Broadsheet, No 237.

most common lethal genetic disease of caucasian populations. ${ }^{78}$ In newborn infants it presents as meconium ileus and the usual pattern of lung disease develops later. The diagnosis depends on the classic sweat test which shows the characteristic abnormally high sodium concentrations. This test combined with those for meconium albumin and pancreatic function requires care and experience with good clinicallaboratory liaison.

The high detection rate for endocrine disease may be due to the early arousal of suspicion by the clinically obvious effects of hormones, like virilisation of external genitalia. Similarly, many infants deficient in adenosine deaminase activity (ADA) manifest in severe combined immunodeficiency, have been diagnosed, although this condition is very rare-about 1000 times rarer than phenylketonuria. ${ }^{79}$ An extensive screening programme to detect ADA deficiency in infants in New York was not helpful and was abandoned.

The known incidence of the storage disorders caused by acid hydrolase deficiencies has been estimated at 27 in 100000 births, which is high (table 3). In older children the protracted and characteristic clinical course of the storage disorders has been associated with many successful diagnoses in large numbers of index cases. As a consequence of successful diagnosis of index cases, antenatal diagnoses have become highly developed.

\section{USE OF INCIDENCE DATA FOR TREATABLE}

CONDITIONS TO LIMIT INITIAL INVESTIGATIONS As many paediatric teams care for $2-4000$ births per year they are unlikely to encounter diseases rarer than 1 in $10-20000$, in other words one every five years. It therefore seems practical to suggest that once the team is clear that a baby is probably ill, an investigation protocol should be initially restricted to diseases with an incidence of about 1 in 10-20000. This proposal is in line with current screening practice for phenylketonuria, which has an incidence of 1 in 10000 and hypothyroidism, which has an incidence of 2 in 10000 . Of the several thousand possible defects, the number which should be considered by a nonspecialist can probably be limited to between 10 and 30. Considering the incidence of diagnosable and, as a first priority, treatable diseases in the population in one's care generally yields a small group of diseases in the United Kingdom (tables 3 and 4) and for Switzerland. ${ }^{80}$

The introduction of methods capable of detecting organic acidoses may increase the detection rate of these diseases. ${ }^{81}$ Three groups are commonly encountered: methylmalonic acidaemias, some of which are $B_{12}$ responsive; multiple carboxylase deficiencies, which may be biotin responsive; and the generally fatal propionic acidaemias. The total incidence may be as high as 1 in 10000 . From this evidence the necessary methods for preliminary diagnosis can be defined.

It might be helpful to indicate a condition which is impracticable to detect usefully by whole population screening. Maple syrup urine disease is too rare and too rapidly fatal for the index case to be saved in most cases. It is practicable, however, to diagnose a second case in an affected family. Newborn infants in whom serious metabolic disease is anticipated can be fed glucose and thoroughly and rapidly investigated. Such a procedure organised from a reference laboratory caring for 75000 births a year detected only six babies at risk, of whom four were normal. One had massive hepatic necrosis of unknown cause and the other citrullinaemia. ${ }^{82}$

\section{POPULATION SCREENING}

Phenylketonuria and congenital hypothyroidism are common enough - 1 and 2 in 10000 -respectively, to produce a considerable number of live born irre-

Table 4 Incidence of diagnosed inherited metabolic disorders over two years in the United Kingdom

\begin{tabular}{llll}
\hline & Births & & \\
\cline { 2 - 4 } $\begin{array}{l}\text { Group } \\
\text { diagnosis }\end{array}$ & $\begin{array}{l}\text { Manchester } \\
(n=110000)\end{array}$ & $\begin{array}{l}\text { Sheffield } \\
(n=60000)\end{array}$ & $\begin{array}{l}\text { Bristol } \\
(n=70000)\end{array}$ \\
\hline $\begin{array}{l}\text { Amino acids } \\
\text { Organic acids }\end{array}$ & 5 & 4 & 1 \\
$\begin{array}{l}\text { Urea cycle } \\
\text { Galactosaemia }\end{array}$ & 2 & 2 & Not tested \\
\hline
\end{tabular}

Data modified from Association of Clinical Biochemists Newsheet No 237. 
versibly damaged infants who require continued institutional care. These two conditions are not common enough, however, to be an effective part of a paediatrician's clinical response to their very vague and often late clinical signs. The unexpected success of the laboratory screening programmes for phenylketonuria and later for hypothyroidism mitigates against a policy of dismissing all such metabolic disease as too rare to justify diagnostic consideration.

With so many possible diseases it is hardly surprising that such insidious and vague early signs are missed in newborn infants. Reference laboratories often care for patients who have shown early signs (table 2) that were not investigated, but it is impractical to investigate all patients with such signs. A major problem is the selection of a high risk group. This needs positive diagnoses for the common causes of the ill defined clinical signs that provide the initial clues. Before it can be justified to adopt screening procedures for specific disease most centres regard a good cheap overall screening method with a minimum of false positive or negative results and an effective treatment as vital.

Screening programmes also have limitations. Samples are generally taken on the fifth to eighth day of life when rapid changes are taking place. The analytical problems of measuring large numbers of compounds are considerable. In addition, substrate loading by milk feeding is also necessary in galactosaemia. The success of adapting the hypothyroid and steroid 21-hydroxylation deficiency screening programme to the dried blood sample used for phenylalanine analyses suggests that many more compounds could be included if abnormalities were common enough. Various methods are already available. $^{8384}$

Histidinaemia can be reduced with an appropriate diet, but a recent careful and extensive prospective study of histidinaemia detected by whole population screening in North America and Japan has shown that there seems to be no associated disease. Previous associations were due to selective investigation of an abnormal group. ${ }^{85-88}$ Histidinaemia is not a "disadaptive" phenotype or disease. As well as abnormality being treatable when detected in the second week of life it is also necessary for there to be an associated clinical abnormality. Antenatal treatment for most defects is at the experimental stage.

In summary, the present pattern seems to be firstly, national population screening by central laboratories for common genuinely treatable disorders with an insidious clinically indistinguishable onset and course. The latest candidate for population screening is steroid 21-hydroxylase defects. ${ }^{89}$ Secondly, stepwise investigation of chronic, progressive severe disease is needed, in which a conventional clinical approach of- ten provides a diagnosis, even in very rare conditions. In some United Kingdom centres, alert clinicians have detected about as many patients with congenital adrenal hyperplasia as those with phenylketonuria: therefore screening may be avoidable. Thirdly, only tried and tested beneficial procedures should be accepted into everyday clinical practice.

As there are a large number of rapidly fatal metabolic diseases in the newborn period and a high mortality we need more effective positive procedures for this age group. Two cases, which were recently considered at the United Kingdom Medical Research Council Clinical Research Centre, of the generally fatal but treatable condition of congenital adenocortical hypoplasia, were admitted to special care baby units in their respective hospitals with intrapartum asphyxia. This diagnosis is made in a "collapsed" infant and both oxygen and cortisol deficiency cause metabolic failure. After four to five days these infants were investigated for persistent unconjugated hyperbilirubinaemia, a developmental failure due to cortisol deficiency. ${ }^{90}$ Until intrapartum hypoxia can be reliably and rapidly diagnosed, such neonates with a treatable condition will probably die, diagnosed as asphyxia. In adrenocortical hypoplasia, unlike many other metabolic diseases, a diagnosis at necropsy is possible and is commonly made.

\section{Diagnosis of rare metabolic causes of disease and the role of the reference laboratories}

A severely ill infant aged four to five days or more, without gross congenital anatomical defects or infection, probably has one of more than a 1000 rare diseases. The only practicable mechanism for the diagnosis and management of these diseases has been the creation of reference centres. ${ }^{9192}$ In this review I have indicated how patients should be selected for referral. Widening the criteria for acceptance of patients for detailed investigation of organic acidaemias, however, has not increased the number of cases detected. ${ }^{93}$ Preliminary local investigation by a well informed paediatric and laboratory team can result in a higher proportion of positive diagnoses. ${ }^{93}$ The investigative flow diagram in fig 2 is similar to that agreed by a United Kingdom working party. ${ }^{94}$ It was emphasised that the district general hospital should take investigation to the second line; the reference laboratory then takes over at the third and final line. ${ }^{94}$ It was also emphasised that the reference laboratory is available for consultation, and to accept material it must have been initially consulted. Many problems, when defined clearly on the telephone or in a summary letter, are soluble with the clinical and biochemical experience of the reference laboratory and require no further investigation. The reference 
centre can guide initial investigation and interim treatment. Many endocrine diseases are amenable to diagnosis by a team which can recognise the clinical effects of hormones and systematically test even rare possibilities. ${ }^{95}$

If the newborn period alone is considered, published tables of possible causes of metabolic disease are lengthy. Haan and Danks ${ }^{96}$ listed 38 conditions; these tables have been condensed by Holton. ${ }^{97}$ Consideration of the actual United Kingdom incidences listed in tables 3 and 4 shows that most of these can be initially disregarded. The evidence in fig 2 and tables 3 and 4 suggest that the following tests should be available at a district general hospital.

1 Careful check for sodium loss due to steroid 21-hydroxylation deficiency which has an incidence of about 1 in $10000{ }^{8489}$ Urinary concentrations of sodium greater than $20 \mathrm{mmol} / 1$ should be regarded as high in a normally fed full term infant.

2 An amino acid chromatogram of blood and urine will show various disorders of amino acid metabolism.

3 Check for persistent metabolic acidosis (at least plasma bicarbonate) as a reduced concentration is usually seen in organic acidaemia. Simple chromatographic methods for organic acids are useful.

4 Possibly check plasma ammonia. This is very high in urea cycle defects and hepatic failure.

5 Do a test for galactose. This is a reducing substance that, if shown not to be glucose in the urine of a mature milk fed infant, indicates galactosaemia.

6 Perform a sweat test for cystic fibrosis.

These tests cover most of the conditions which are at present recognised and emphasise those which are treatable. Mucopolysacchridoses and other storage disorders do not usually present as acute metabolic disorders in the newborn.

If there are doubts about the results of these tests then the reference laboratory should be consulted and the results checked by those with more experience, especially in interpreting amino acid patterns. If all the test results are negative and the infant is still deteriorating transfer of the patient to the care of a specialised clinical and laboratory team is advisable. Incurable damage due to failure to detect a treatable condition should thus be avoided.

It is the role of the reference laboratory to reach systematically ${ }^{98}$ one of the many possible diagnoses. ${ }^{99}$ Current evidence suggests that this is an unsolved problem. ${ }^{100}$

The use of a conventional 12 channel clinical chemistry analyser to generate an "admission" profile at a paediatric referral centre made only a small contribution to overall care. ${ }^{101}$ Most conventional clin- ical chemistry analyses are of limited use in diagnosis despite their value in the problems of immaturity. Extensive chromatographic skills can show a variety of defects - the profiling of organic and amino acids and of steroids, for example. For confirming diagnoses, the ability to estimate enzyme activities in tissues generally on a micro scale may be required by reference centres, which will also need extensive clinical experience.

\section{Conclusions}

The field of neonatal diagnosis and treatment is continually developing. The acquisition of diagnostic skills is shown in the clustering of case reports of new diseases.

Management of suspected metabolic disease is to feed the patient only glucose and water for about 12-48 hours, when preliminary results should be available. ${ }^{82100}$ In cases in which death is imminent the aim should still be to secure a diagnosis. Diagnosis after death of an index case of maple syrup disease can help the affected family. For such diagnosis Burton and Nadler ${ }^{102}$ recommended that measurements of urine, plasma, and sterile skin kept at $37^{\circ} \mathrm{C}$ or at least at room temperature in tissue culture medium or even $5 \%$ glucose in physiological saline should be secured. The preliminary use of an ethyl chloride spray sterilises skin; alternatively, fascia can be used. Fibroblasts grow if obtained up to about 48 hours after death. If a necropsy is performed a specimen of fresh liver stored at $-20^{\circ} \mathrm{C}$ is also recommended. If the necropsy shows grossly affected tissues these should be retained. Vitreous humour can be taken at necropsy ${ }^{103}$ and gives clearer amino acid patterns than other available extracellular fluids. Every effort should be made, however, to take specimens of blood, urine, and even cerebrospinal fluid before death. In general, analyses of necropsy specimens are extremely difficult to interpret. ${ }^{97104105}$ In severely ill infants a high index of suspicion for inherited metabolic disease and a readiness to do some tests can produce useful results. ${ }^{106}$

This article could not have been written without the working collaboration of many clinical and laboratory medicine colleagues. I acknowledge permission for the use of fig 2 from the Journal of Inherited Metabolic Disease, with permission from the Society for the Study of Inborn Errors of Metabolism and MTP Press.

The original work reported was undertaken in accordance with the regulations of the Northwick Park Hospital and Clinical Research Centre Ethical Committee. 


\section{Bibliography}

Practical guides for clinicians providing insight into the immediate care of newborn

Inspect the guides local clinicians use.

Brown EJK, Valman HB. Practical neonatal paediatrics. Oxford: Blackwell Scientific Publications, 1979.

Chiswick ML. Neonatal medicine. London: Update, 1978.

Davies PA, Robinson RJ, Scopes JW, Tizard JPM, Wigglesworth JS. Medical care of newborn babies. Clinics in developmental medicine. 1972.

Keay AJ, Morgan DM. Craig's care of the newly born infant. Edinburgh: Churchill Livingstone, 1982.

Phillip AGS. Neonatology a practical guide. London: Henry Kimpton, 1980.

Insley J, Wood B. A paediatric vade mecum. 10th Ed. London: Lloyd Luke, 1982.

Roberton NRC. Textbook of neonatology. Edinburgh: Churchill Livinstone, 1986.

O'Brien D, Ibbot FA, Rodgerson DO. Laboratory manual of paediatric microbiochemical techniques. New York: Harper \& Row, 1963. (A guide to early work.)

Meites S, ed. Paediatric clinical chemistry. 3rd Edn. AACC Press, 1988.

\section{Major textbooks with references of original articles}

Bondy PK, Rosenberg LE. Metabolic control and disease. London: WB Saunders, 1980.

Cockburn F, Drillien CM. Neonatal medicine. Oxford: Blackwell Scientific Publications, 1974.

Goodwin JW, Godden JD, Chance GW. Perinatal medicine-the basic science underlying clinical practice. Baltimore: Williams \& Wilkins, 1976.

Klaus MH, Fanroff AM. Care of the high risk neonate. London: WB Saunders, 1979.

Schaffer AJ, Avery ME. Diseases of the newborn. London: WB Saunders, 1977.

Wold NJ. Antenatal and neonatal screening. London: Oxford University Press, 1984.

\section{Series of review articles}

Clinics in perinatology. London: WB Saunders.

Clinics in obstetrics and gynecology. London: WB Saunders. (Relatively little on newborn.)

Pediatric Clinics of North America. London: WB Saunders. Advances in pediatrics. Chicago: Yearbook publishers.

\section{References}

1 D'Souza SW, McCartney E, Nolan M, Taylor IG. Hearing, speech and language in survivors of severe perinatal asphyxia. Arch Dis Child 1981;56:245-52.

2 Steendijk R. Diagnostic and aetiologic features of idiopathic and symptomatic growth hormone deficiency in the Netherlands. Helv Paediatr Acta 1980;35:129-39.

3 Hey EN. Physiological principles involved in the care of the preterm human infant. In: Austin CR, ed. Mammalian fetus in vitro. London: Chapman and Hall, 1973:251-356.

4 Evans SE, Durbin GM. Aspects of the physiological and pathol- ogical background to neonatal clinical chemistry. Ann Clin Biochem 1983;20:193-207.

5 Clayton BE, Jenkins P, Round JM. Paediatric chemical pathology - clinical tests and reference ranges. Oxford: Blackwell Scientific Publications, 1980.

6 New England Congenital Hypothyroidism Collaborative. Effects of neonatal screening for hypothyroidism; prevention of mental retardation before clinical manifestations. Lancet 1981;ii:1095-8.

7 Brock DJH. Impact of maternal serum alpha-fetoprotein screening on antenatal diagnosis. Br Med J 1982;285:365-7.

8 Weatherall JAC. A review of some effects of recent medical practices in reducing the numbers of children born with congenital abnormalities. Health Trends 1982;14:85-8.

9 Smith ADS, Shenkin A, Dryburgh FJ, Morgan HG. Emergency biochemistry services-are they abused? Ann Clin Biochem 1982;19:325-8.

10 Grivell AR, Forgie HJ, Fraser CG, Berry MN. Effect of feedback to clinical staff of information on clinical biochemistry requesting patterns. Clin Chem 1981;27:1717-20.

11 Strang LB. Neonatal respiration physiological and clinical studies. Oxford: Blackwell Scientific Publications, 1977.

12 Holton JB. Diagnostic tests on amniotic fluid. Essays Med Biochem 1977;3:75-107.

13 Fairweather DVI, Eskes TKAB. Amniotic fluid research and clinical application. 2nd Ed. Amsterdam: Excerpta Medica 1978.

14 Taylor NF. Placental sulphatase deficiency. J Inher Metab Dis 1982;5:164-75

15 Harkness RA, Taylor NF, Crawford MA, Rose FA. X-linked ichthyosis, cervical dystocia and placental sterolid sulphatase deficiency. Br Med J 1983;287:2-3.

16 Harkness RA. Fertility, pregnancy and contraception. In: Brown SS, Mitchell FL, Young DS, eds. Chemical diagnosis of disease. Amsterdam: Elsevier, 1979:833-50.

17 Harkness RA, Lawrence CR, Renshaw A, Barr IC, Brown SS, Rinsler MG. Assessment of the performance and clinicalo utility of a ward side room bilirubinometer. Ann Clin Biochem 1983;20:149-52.

18 Anderson JR, Linsell WD, Mitchell FL. Guidelines on the performance of chemical pathology assays outside the laboratory. Br Med J 1981;282:743.

19 King G, Steggles D, Harrop JS. Performance and storage of reagent strips for measuring blood glucose. $\mathrm{Br}$ Med J 1982;285:1165.

20 Salle BL, David L, Chopard JP, Grafmeyer DC, Renaud H Prevention of early neonatal hypocalcaemia in low birth weight infants with continuous calcium infusion: effect on serum calcium, phosphorus, magnesium and circulating immunoreactive parathyroid hormone and calcitonin. Pediatr Res 1977;11:1180-5.

21 Mathew PM, Wharton BA. Investigation and management of neonatal jaundice: a problem oriented case record. Arch Dis Child 1981;56:949-53.

22 Stiehm ER, Ryan J. Breast milk jaundice. Am J Dis Child 1965;109:212-6.

23 Jelliffe DB, Jelliffe EFP. Human milk in the modern world. Oxford: University Press, 1978:4-8.

24 Coles EC, Cotter S, Valman HB. Increasing prevalence of breast feeding. Br Med J 1978;2:1122.

25 Editorial Correspondence and cited references. Breast-feeding jaundice. J Pediatr 1982;100:334-46.

26 Rosenfeld RS, Arias IM, Gartner LM, Hellman L, Gallagher TF. Studies of urinary pregnane-3 $\alpha, 20 \beta$-diol during pregnancy, postpartum, lactation and progesterone ingestion. J Clin Endocrinol 1967;27:1705-10.

27 Smith JA, King RJB. The metabolism of testosterone by tissue from normal and neoplastic mouse breast. $J$ Endocrinol 1966;35:281-7.

28 Chatterton RT, Chatterton AJ, Hellman L. Metabolism of progesterone by the rabbit mammary gland. Endocrinology 

1969;85:16-24.

29 Lauritzen Ch, Lehmann WD. The significance of steroid hormones for the development of hyperbilirubinaemia and icterus in the newborn infant. $J$ Endocrinol 1967;39:183-8.

30 Hargreaves T, Piper RF. Breast milk jaundice effect of inhibitory breast milk and $3 \alpha, 20 \beta$-pregnanediol on glucuronyl transferase. Arch Dis Child 1971;46:195-8.

31 Dutton GJ. Glucuronic acid. London: Academic Press, 1966: 185-99.

32 Rao GS, Rao ML, Breuer H. Partial purification and kinetics of oestriol $16 \alpha$-glucuronyltransferase from the cytosol fraction of human liver. Biochem $J$ 1970;118:625-34.

33 Darling JAB, Harkness RA. A method for the group analysis of steroids in milk. Acta Endocrinol 1973;72:390-400.

34 Darling JAB, Kelly RW, Laing AH, Harkness RA. The isolation and identification of progesterone obtained from cows' milk during pregnancy. $J$ Endocrinol 1972;54:347-8.

35 Heap RB, Gwyn M, Laing JA, Walters DE. Pregnancy diagnosis in cows; changes in milk progesterone concentration during the oestrous cycle and pregnancy measured by rapid immunoassay. Journal of Agricultural Science (Cambridge) 1973;81:151-7.

36 Kulshi JK, Smith M, Hartmann PE. Perinatal concentrations of progesterone, lactose and $\alpha$-lactalbumin in the mammary secretion of women. $J$ Endocrinol 1977;74:509-10.

37 Murphy JF, Hughes I, Jones ERV, Gashell S, Pike AW. Pregnanediols and breast milk jaundice. Arch Dis Child 1981; 56:474-6.

38 Van der Molen HJ, Hart PG, Wijmenga HG. Studies with 4- ${ }^{14} \mathrm{C}$-Lynestrenol in normal and lactating women. Acto Endocrinol (Copenhagen) 1969;61:255-74.

39 Wijmenga HG, Van der Molen HG. Studies with $4-^{14} \mathrm{C}-$ Mestranol in lactating women. Acta Endocrinol 1969;61: 665-77.

40 Knowles JA. Excretion of drugs in milk-a review. $J$ Pediatr 1965;66:1068-82.

41 Wickizer TM, Brilliant LB, Copeland R, Tilden R. Polychlorinated biphenyl contamination of nursing mothers milk in Michigan. Am J Public Health 1981;71:132-7.

42 British National Formulary. London. 1983:17-20.

43 Greer FR, Reeve LE, Chesney RW, De Luca HF. Water-soluble vitamin D in human milk: a myth. Pediatrics 1982;69:238.

44 Hallman M. Effects of intraperitoneal chloramphenicol on some mitochondrial enzymes in neonatal rats. Biochem Pharmacol 1971;20:1797-809.

45 Anderson JM, Cockburn F, Forfar JO, Harkness RA, Kelly RW, Kilshaw B. Neonatal spongioform myelinopathy after restricted application of a hexachlorophane skin disinfectant. $J$ Clin Pathol 1981;34:25-9.

46 Soyka LF. Developmental pharmacology of the methylxanthines. Semin Perinatol 1981;5:303-8.

47 Brown JK. Infants damaged during birth. In: Hull D, ed. Recent advances in paediatrics. Edinburgh: Churchill Livingstone, 1976:35-86.

48 Beard RW, Rivers RPA. Fetal asphyxia in labour. Lance 1979;ii:1117-9.

49 Chamberlain R, Chamberlain G, Howlett B, Claireaux A. British births 1970. Vol. 1. London: Heinemann, 1970:97-100.

50 Jennett RJ, Warford HS, Kreinick C, Waterkotte GW. Apgar index: a statistical tool. Am J Obstet Gynecol 1981;140: 206-12.

51 Swanstrom S, Bratteby LE. Hypoxanthine as a test of perinatal hypoxia as compared to lactate base deficit and $\mathrm{pH}$. Pediatr Res 1982;16:156-60.

52 O'Connor MC, Harkness RA, Simmonds RJ, Hytten FE. The measurement of hypoxanthine, xanthine, inosine and uridine in umbilical cord blood and fetal scalp blood samples as a measure of fetal hypoxia. Br J Obstet Gynaecol 1981;88: 381-90.

53 Bossart M, Perret C. Lactate in acute conditions. Basel: Karger,
1979.

54 Harkness RA, Whitelaw AGL, Simmonds RJ. Intrapartum hypoxia: the association between neurological assessment of damage and abnormal excretion of ATP metabolites. J Clin Pathol 1982;35:999-1007.

55 Harkness RA, Lund RJ. Cerebrospinal fluid concentrations of hypoxanthine, uridine and inosine: high concentrations of the ATP metabolite, hypoxanthine, after hypoxia. J Clin Pathol 1983;36:1-8.

56 Meberg A, Saugstad OD. Hypoxanthine in cerebrospinal fluid of children. Scand J Clin Lab Invest 1978;38:437-40.

57 Harkness RA, Simmonds RJ, Coade SB. Purine transport and metabolism in man: the effect of exercise on concentrations of purine bases, nucleosides and nucleotides in plasma, urine, leucocytes and erythrocytes. Clin Sci 1983;64:333-40.

58 Harkness RA, Coade SB, Walton KR, Wright D. Xanthine oxidase deficiency and "Dalmatian" hypouricaemia: incidence and effect of exercise. J Inher Metab Dis 1983;6:114-20.

59 Hallgren R, Niklasson F, Terent A, Akerblom A, Widerlow E. Oxypurines in cerebrospinal fluid as indices of disturbed brain metabolism. Stroke 1983;14:382-8.

60 Levin SD, Brown JK, Harkness RA. Cerebrospinal fluid hypoxanthine and xanthine concentrations as indicators of metabolic damage due to raised intracranial pressure in hydrocephalic children. J Neurol Neurosurg Psychiatr 1984; 47:730-3.

61 Warnick CT, Lazarus HM. Recovery of nucleotide levels after cell injury. Can J Biochem 1981;59:116-21.

62 Kloner RA, Ganote E, Whalen DA, Jennings RB. Effect of a transient period of ischaemia on myocardial cells. Am J Pathol 1974;74:399-422.

63 Harkness RA, Simmonds RJ, Coade SB, Lawrence CR. The ratio of the concentration of hypoxanthine to creatinine in urine from newborn infants: a possible indicator for the metabolic damage due to hypoxia. Br J Obstet Gynaecol 1983; 90:447-52.

64 Thiringer K. Hypoxanthine as a measure of foetal asphyxia. Sheep experiments and clinical study in human neonates. Goteborg: University of Goteborg, 1982 (Thesis.) ppl 83.

65 Harkness RA, Coade SB, Simmonds RJ, Duffy S. Effect of a failure of energy supply on adenine nucleotide breakdown in placentae and other fetal tissues from rat and guinea pig. Placenta 1985;6:199-216.

66 Simmonds RJ, Coade SB, Harkness RA, Drury L, Hytten FE. Nucleotide, nucleoside and purine base concentrations in human placentae. Placenta 1981;3:29-39.

67 O'Connor MC, Harkness RA, Simmonds RJ, Hytten FE. Raised hypoxanthine, xanthine and uridine concentrations in meconium stained amniotic fluid and during labour. $\mathrm{Br} J$ Obstet Gynaecol 1981;88:375-80.

68 Harkness RA, Geirsson RT, McFadyen IR. Concentrations of hypoxanthine, xanthine, uridine and urate in amniotic fluid at Caesarean section and the association of raised levels with prenatal risk factors and fetal distress. Br J Obstet Gynaecol 1983;90:815-20.

69 Rose FA. Review: The mammalian sulphatases and placental sulphatase deficiency in man. $J$ Inher Metab Dis 1982;5: 145-52.

70 Kruus S, Bergstrom L, Suutarinen T, Hyvonen R. The prognosis of near drowned children. Acta Paediatr Scand 1979;68: 315-22.

71 Reibel DK, Roveto MJ. Myocardial ATP synthesis and mechanical function following oxygen deficiency. Am J Physiol 1978;234:H620-4.

72 Fysh WJ, Turner GM, Dunn PM. Neurological normality after extreme birth asphyxia. Case report. Br J Obstet Gynaecol 1982;89:24-6.

73 Porter R, Whelan J. Human muscle fatigue: physiological mechanisms. Ciba Foundation Symposium 82. London: Pitman Medical, 1981. 
74 Myers RE, Wagner KR, Courten G. Lactic acid accumulation in tissue as a cause of brain injury and death. In: Lauersen NH, Hochberg HM, eds. Clinical perinatal biochemical monitoring. Baltimore: Williams and Wilkins, 1981:11-34.

75 Bode JC, Zelder O, Rumpett HJ, Wittkamp U. Depletion of liver adenosine phosphates and metabolic effects of intravenous infusion of fructose or sorbitol in man and in the rat. Eur J Clin Invest 1973;3:436-41.

76 Vogt MT, Farber E. On the pathology of ischaemic renal cell death. Reversible and irreversible cellular and mitochondrial metabolic alterations. Am J Pathol 1968;53:1-26.

77 Pampiglione G, Chaloner J, Harden A, O'Brien J. Transitory ischaemia/anoxia in young children and the prediction of the quality of survival. Ann NY Acad Sci 1978;315:281-92.

78 Nadler HL, Rao GJS, Taussig LM. Cystic Fibrosis. In: Stanbury JB, Wyngaarden JB, Frederickson DS, eds. Metabolic basis of inherited metabolic disease. New York: McGraw-Hill, 1978:1683-710.

79 Guttler F, Seakins JWT, Harkness RA. Inborn errors of immunity and phagocytosis. Lancaster: MTP, 1979.

80 Bachmann C, Colombo JP. Incidence of disorders tested by systematic screening: confidence limits and comparison of programmes. J Inher Metab Dis 1982;5:3-5.

81 Krieger I, Nigro $M$, Taqi Q. Screening for metabolic disease in a metropolitan hospital. Am J Dis Child 1982;136:125-8.

82 Danks DM. Management of newborn babies in whom serious metabolic illness is anticipated. Arch Dis Child 1974;49: 576-8.

83 Murphey WH, Patchen L, Guthrie R. Screening tests for arginosuccinic aciduria, orotic aciduria and other inherited enzyme deficiencies using dried blood specimens. Biochem Genet 1972;6:51-9.

84 Pang S, Murphey W, Levine LS, Spence DA, Leon A, LaFranchi S, Surve AS, New MI. A pilot newborn screening program for congenital adrenal hyperplasia in Alaska. J Clin Endocrinol 1982;55:413-20.

85 Tade L. Intellectual development in patients with untreated histidinemia. A collaborative group study of neonatal screening for inborn errors in Japan. J Pediatr 1983;101:562-3.

86 Scriver CR, Levy HL. Histidinemia Part I: reconciling retrospective and prospective findings. $J$ Inher Metab Dis 1983; 6:51-3.

87 Rosenmann A, Scriver CR, Clow CL, Levy HL. Histidinemia Part II: Impact, retrospective study. J Inher Metab Dis 1983;6:54-7.

88 Coulombe JT, Kammerer BL, Hirsch BZ, Levy HL, Scriver CR. Histidinemia Part III: Impact; prospective study. $J$ Inher Metab Dis 1983;6:58-61.

89 Workshop on screening for congenital adrenal hyperplasia (steroid 21-hydroxylase deficiency). J Inher Metab Dis 1986; 9(suppl 1):111-55.

90 Harkness RA, Taylor NF, Bowman PR, Gordon H, Cummins $M$, Valman HB. The causes of low oestrogen excretion in pregnancy: the development of diagnostic methods for the antenatal detection of congenital adrenocortical hypoplasia. Clin Endocrinol 1980;12:453-60.

91 Raine DN. Management of inherited metabolic disease. Br Med
J 1972;i:329-36.

92 Raine DN. Some principles in the management of inherited metabolic disease. In: Cockburn F, Gitzelmann R, eds. Inborn errors of metabolism in humans. Lancaster: MTP, 1982: 267-85.

93 Chalmers RA, Purkiss P, Watts RWE, Lawson AM. Screening for organic acidurias and amino acidopathies in newborn and children. J Inher Metab Dis 1980;3:27-43.

94 Proposals for a co-ordinated scheme for the postnatal diagnosis of inherited metabolic disease in infancy. Association of Clinical Biochemists News Sheet 1983;237:6-12.

95 Harkness RA, Thistlethwaite D, Darling JAB, Skakkebaek NE, Corker CS. Neutral $17 \beta$-hydroxysteroid oxidoreductase deficiency in testes causing male psuedohermaphroditism in an infant. $J$ Inher Metab Dis 1979;2:51-4.

96 Haan EA, Danks DM. Clinical investigation of suspected metabolic disease. In: Barson AJ, ed. Laboratory investigation of fetal disease. Bristol: PG Wright, 1981:410-28.

97 Holton JB. Diagnosis of inherited metabolis disease in severely ill children. Ann Clin Biochem 1982;19:389-95.

98 Applegarth DA, Toone JR, MacLeod PM. Laboratory diagnosis of inborn errors of metabolism in children. Pediatric Pathology 1983;1:107-30.

99 McKusick VA. Mendelian inheritance in man-catalogs of the autosomal dominant, autosomal recessive and $X$-linked phenotypes. Baltimore: Johns Hopkins University Press, 1983.

100 Danks DM. Plan of management for newborn babies in whom metabolic disease is anticipated or suspected. In: Ampola MG, ed. Early detection and management of inborn errors. Clin Perinatol 1976;3:251-60.

101 Leonard JV, Clayton BE, Colley JRT. Use of a biochemical profile in a childrens' hospital: results of two controlled trials. Br Med J 1975;2:662-6.

102 Burton BK, Nadler HL. Clinical diagnosis of the inborn errors of metabolism in the neonatal period. Pediatrics 1978;61: 398-405.

103 Mason JK, Harkness RA, Elton RA, Bartholomew S. Cot deaths in Edinburgh: infant feeding and socioeconomic factors. J Epidemiol Community Health 1980;34:35-41.

104 Harkness RA, Darling JAB, Bain AD, Syme J. Plasma lecithincholesterol acyltransferase deficiency in a child with terminal pulmonary hyaline membrane disease. Arch Dis Child 1973;48:906-10.

105 Adams A, Harkness RA. Adenosine deaminase activity in thymus and other human tissues. Clin Exp Immunol 1976;26: 647-9.

106 Nyhan WL. Heriditable metabolic disease in the differential diagnosis of asphyxia. In: Gluck L, ed. Intrauterine asphyxia and the developing brain. Chicago: Year Book Publishers Inc, 1977:421-9.

Requests for reprints to: Dr RA Harkness, Division of Inherited Metabolic Disease, MRC Clinical Research Centre, Watford Road, Harrow, Middlesex HA1 3UJ, England. 